\title{
A Problemática do Cárcere Privado para Familiares e Trabalhadores da Saúde Mental
}

\author{
João Paulo Macedo ${ }^{1}$ \\ Adrielly Pereira de Sousa \\ Programa de Pós-Graduação em Politicas Públicas da Universidade Federal do Piauí, \\ Teresina, PI, Brasil \\ Adrielli M. B. de Oliveira Silva \\ José Luís C. C. Teixeira \\ Gabriela Fernandes Veras \\ Universidade Federal do Piauí, Parnaíba, PI, Brasil
}

\section{Resumo}

As demandas da saúde mental na atenção primária em saúde são diversas e complexas. Os profissionais se deparam com muitas delas: usuários crônicos egressos de longa internação, transtornos mentais comuns, crise psicótica, comportamento suicida, medicalização e as mais diversas situações de risco psicossocial geradoras de sofrimento psíquico. No entanto, há uma entre as situações anteriormente referidas que se perpetua ao longo da história da assistência psiquiátrica: casos de cárcere privado. Objetiva-se com o presente estudo perceber como familiares e trabalhadores da rede de atenção psicossocial de Parnaíba (PI) lidam com a problemática do cárcere privado. Trata-se de um estudo descritivo exploratório, de natureza qualitativa, com base na produção de sentidos. Participaram 10 familiares e 15 profissionais (que prestam assistência a casos de cárcere privado no município). Os resultados indicaram a ocorrência significativa de casos de cárcere, a fragilidade da assistência na perspectiva de reverter tal situação, e a quase nenhuma oferta de cuidados aos familiares sufocados pela sobrecarga e intenso sofrimento por realizarem a dura tarefa de serem cuidadores nestas condições. Espera-se com esse estudo dar conhecimento a uma das realidades mais duras e difíceis, e urgente de respostas, da Rede de Atenção Psicossocial.

Palavras-chave: Saúde mental, atenção primária, trabalho em rede, cárcere, exclusão.

\section{The Problem of False Imprisonment for Family and Mental Health Workers}

\begin{abstract}
Demands for mental health in primary attention are diverse and complex. Professionals come across demands multiple: chronicle users returned from a long hospitalization, common mental disorders, psychotic crises, suicidal behaviour, medicalization and psychosocial risk situation generates psychic
\end{abstract}

1 Endereço para correspondência: Universidade Federal do Piauí, Departamento de Psicologia, Campus Parnaíba, Av. São Sebastião, 2819, São Benedito, Parnaíba, PI, Brasil 64202-020. E-mail: jpmacedo@ufpi. edu.br, adriellypsi@hotmail.com, adrielli.silva21@hotmail.com, campelocostateixeira@hotmail.com e gabi_ veras@hotmail.com Agradecemos ao Programa de Iniciação Científica e Programa Jovens Talentos da Universidade Federal do Piauí (UFPI). 
suffering. However, there is one, between all problems, that have been perpetuated through history of psychiatric assistance: deprived incarceration. The current study aims at understanding the perception of families and professionals about the psychosocial assistance network in Parnaíba (PI) regarding the deprived incarceration issue. This is an exploratory and descriptive study, of qualitative nature, based on the production of meanings. Participants were 10 relatives and 15 professionals giving assistance to cases of deprived incarceration in the county. Results indicated significant occurrence of incarceration cases, the fragility of the assistance in order to revert this situation, and the almost inexistent opportunity of caring for the families, who are suffocated with the overload and intense suffering of being care givers. We expect this study can provide knowledge about one of the harshest realities so psychosocial attention network can address answers.

Keywords: Mental health, primary attention, network, incarceration, exclusion.

\section{El Problema de la Privación de Liberad para la Familia y los Trabajadores de Salud Mental}

\section{Resumen}

Las exigencias de la salud mental en la atención primaria son diversas y complejas: usuarios crónicos, trastornos mentales comunes, episodios psicóticos, conducta suicida, medicalización y situaciones de riesgo psicosocial. Sin embargo, hay una de las situaciones mencionadas anteriormente que se perpetúa a lo largo de la historia de la atención psiquiátrica: los casos de privación de libertad. El objetivo del presente estudio es ver cómo la familia y los empleados de la red de atención psicosocial de Parnaíba (PI) tratan el problema de la privación de libertad. Se trata de un estudio exploratorio descriptivo, de naturaleza cualitativa, basada en la producción de sentidos. Han participado un total de 10 familias y 15 profesionales (que prestan asistencia a los casos detectados). Los resultados indicaron la presencia significativa de los casos de prisión, la fragilidad de la asistencia con el fin de revertir esta situación, y casi ninguna prestación de la atención a la familia asfixiada por la sobrecarga y el sufrimiento intenso para hacer el trabajo duro de ser cuidadores en estas condiciones. Se espera con ese estudio dar a conocer una de las realidades más duras y difíciles, y de más urgente respuesta, de la Red de Atención Psicosocial.

Palabras clave: Salud mental, atención primaria, trabajo de redes, privación de libertad, exclusión.

Desde os anos 2000, as Políticas de Saúde no Brasil têm se voltado para fortalecer as ações da saúde mental na Atenção Primária em Saúde (APS). A razão é que as equipes cotidianamente se deparam com casos de usuários com histórico de múltiplas internações psiquiátricas sem tratamento extra hospitalar; uso de medicação psiquiátrica por longo tempo sem avaliação médica; problemas graves relacionados ao abuso de álcool e outras drogas; crises psicóticas; comportamento suicida; crises convulsivas e conversivas; além de situações de risco psicossocial (cárcere privado, abuso ou negligência familiar, suspeita de maus tratos, abuso sexual de crianças e adolescentes, violência intrafamiliar, população em situação de rua, etc.) que exigem intervenção urgente e contínua, respeitando, certamente, o campo dos direitos e singularidades dos casos e de cada situação (Ministério da Saúde [MS], 2009).

No geral, sabe-se que a prevalência de transtornos mentais severos, persistentes e comuns na APS, no âmbito mundial e nacional, é relevante. Dados internacionais indicam que $3 \%$ da população mundial apresenta transtornos mentais severos e persistentes necessitando de cuidados contínuos. O estudo realizado pelo Consórcio Internacional de Epidemiologia Psiquiátrica da Organização Mundial de Saúde (OMS) revelou o Brasil como o país com maior prevalência de transtornos mentais na população adulta de 15-59 anos, se comparado aos demais países 
da América Latina (World Health Organization [WHO], 2000). Levantamento realizado pela Organização Pan-Americana de Saúde (OPAS) em conjunto com o MS indicou que $56 \%$ das equipes da Estratégia Saúde da Família (ESF) de todo o país referiram realizar ações em saúde mental (OPAS \& MS, 2002).

Neste caso, faz-se necessário que as equipes identifiquem, acolham e atendam, com o nível de recurso que dispõem, às demandas de saúde mental do território, em seus graus variados de severidade. Devem ainda priorizar as situações mais graves, que exigem cuidados mais imediatos, inclusive as situações de maior vulnerabilidade e risco social, sem desassistir casos de menor gravidade. As intervenções devem ter a família e a comunidade como parceiras no processo de cuidado, sendo fundamental garantir a continuidade do cuidado, com articulação e participação dos demais dispositivos da Rede de Atenção Psicossocial (RAPS) na execução dos projetos terapêuticos, além de envolver outras redes (comunitárias e intersetoriais) com foco no apoio social e reabilitação psicossocial (MS, 2009).

Contudo, mesmo com os avanços alcançados, em termos da ampliação da rede de serviços da atenção psicossocial e modalidades de cuidado com foco extra hospitalar, destacamos um entre os desafios elencados no início deste artigo, que, talvez, constitua um problema recorrente e possivelmente expresse uma das repercussões mais negativas à Reforma Psiquiátrica e à Política de Saúde Mental: são os casos de cárcere privado, envolvendo pacientes com transtorno mental. Trata-se de uma prática secular, mais antiga que a própria psiquiatria, porém, que ainda hoje se perpetua como resposta ao transtorno mental.

Por falta de suporte da rede de cuidados e, muitas vezes, em função da dificuldade de acesso aos serviços, considerando as diversas iniquidades das condições de vida da população, as famílias acabam recorrendo ao cárcere, reproduzindo em seus próprios lares a mecânica manicomial em sua forma total: privação de liberdade, negação de direitos, controle, punição, violência e anulação do sujeito. Assim, o ato de recorrer à situação de cárcere, seja por receio dos comportamentos agressivos de pacientes meio a condição de crise, seja como forma de não expor a "culpa" ou "vergonha" de ter um familiar com transtorno mental em casa, seja ainda pelo cansaço, sobrecarga e desgaste emocional ou descrença quanto a capacidade de resposta dos serviços, indica o quão ainda é presente o modelo manicomial para lidar com a loucura (Dias, Ferigato, \& Biegas, 2010).

Frente a este cenário urgente de transformação, objetivamos com o presente estudo perceber como familiares e trabalhadores da rede de atenção psicossocial de Parnaíba (PI) lidam com a problemática do cárcere privado. Como objetivos específicos, mapear casos de sofrimento psíquico em situação de cárcere privado no município; conhecer as concepções de saúde mental e formas de cuidado dos familiares e trabalhadores; relacionar a dinâmica familiar e os efeitos psicossociais daqueles que lidam com situações de cárcere; e identificar os recursos comunitários e institucionais para assistirem os casos de cárcere no município.

\section{Método}

Trata-se de um estudo descritivo exploratório, de natureza qualitativa, com base na produção de sentidos (Minayo, 2006). A proposta do estudo exigiu o contato direto do pesquisador com o local, pessoas e/ou grupos investigados. A partir desse contato consideramos a profusão de informações, impressões e os sentidos que os participantes da pesquisa têm a respeito das situações e/ou problemáticas que enfrentam no cotidiano e lugar onde vivem/trabalham.

Quanto ao local do estudo, percorremos os diversos pontos da rede de atenção psicossocial do município: 35 Equipes da Estratégia Saúde da Família (ESF), dois Programas de Agentes Comunitários de Saúde (PACS), quatro Equipes do Núcleo de Apoio a Estratégia Saúde da Família (NASF), além do Centro de Atenção Psicossocial II (CAPS). O trânsito por esses serviços possibilitou localizarmos, inicialmente, 15 casos, que depois de visitados um-a-um, confirmamos 12 como cárcere privado. Porém, somente 10 foram entrevistados (familiar cuidador). Quanto 
aos profissionais, entrevistamos 15 técnicos das equipes $\operatorname{ESF}(n=7)$, NASF $(n=5)$ e CAPS $(n=3)$ envolvidos direta ou indiretamente com a realidade das famílias que mantinham seus entes em situação de cárcere.

O trabalho de campo contou com visitas domiciliares para o acompanhamento da rotina dos familiares e usuários em situação de cárcere, além de visitas aos serviços que prestam assistência às famílias dos casos. Recorreu-se ainda a um roteiro semiestruturado para a realização das entrevistas, como também o diário de campo para o registro de informações sobre as condições de vida, hábitos, modos de vida, dinâmica familiar, vínculos sócioafetivos e efeitos psicossociais em torno da problemática dos casos. A entrevista com os familiares foi estruturada com questões que abordavam o perfil sócio econômico, a assistência recebida, a rotina da família, buscando as principais dificuldades e ações em momentos de crise, além de aspectos relacionados às ações de cuidado e os motivos para terem recorrido ao cárcere privado. Quanto aos trabalhadores, buscou-se estruturar o roteiro da entrevista de modo a identificar: (a) o conhecimento das equipes sobre os casos, a assistência oferecida (tipo de aproximação, acompanhamento e suporte) e os desafios e dificuldades quanto ao manejo técnico e relacional; (b) as percepções sobre as famílias e o papel como agentes de cuidado, além das necessidades e o suporte que demandam; (c) a articulação com outros serviços e outros recursos da comunidade.

Para o tratamento de dados utilizou-se a técnica de análise de conteúdo baseado em Minayo (2006), com foco na categorização, inferência, descrição e interpretação dos dados com base na literatura pesquisada. $\mathrm{O}$ estudo teve aprovação do Comitê de Ética de Pesquisa, atendendo aos aspectos éticos e metodológicos de acordo com as Diretrizes estabelecidas na Resolução 196/96, com CAAE no 0338.0.045.000-11.

\section{Discussão dos Resultados}

Parnaíba é a segunda maior cidade do Piauí, com população de 145.705 habitantes conforme o censo de 2010. O município tem importân- cia econômica no turismo (porta de entrada do Delta das Américas) e nos setores educacional e da saúde. Localiza-se na região litorânea, sendo referência no setor saúde para 10 municípios circunvizinhos, que contam, incluindo Parnaíba, com um total de 266.163 habitantes, sendo também referência para localidades do Maranhão e Ceará. Possui 148 estabelecimentos de saúde, sendo $31,7 \%$ do setor público distribuídos em quatro distritos sanitários (regionais de saúde). Em relação à rede psicossocial, conta com um CAPS II e um CAPS AD 24h (que tem caráter regional); quatro equipes NASF, $35 \mathrm{ESF}$ e dois PACS (organizados em 4 regiões de saúde); um Centro de Especialidades com atendimento em Psiquiatria e Psicologia; e Serviço de Atendimento Móvel de Urgência (SAMU). Conta ainda com 12 leitos psiquiátricos na Santa Casa de Misericórdia (hospital filantrópico) e uma Clínica Psiquiátrica (privada), com funcionamento em modalidade de hospital dia, ambos contratados pelo Sistema Único de Saúde (SUS).

Inicialmente visitamos cada uma das Unidades de Saúde da Família (USFs) do município com o intuito de levantar informações sobre situações de cárcere privado envolvendo pessoas com sofrimento psíquico, além de conhecer a atuação das equipes diante dos casos. Sobre esta primeira inserção, tivemos aceitação pela maioria das equipes, com disponibilidade imediata das informações. Porém, em oito USFs, o coordenador técnico ficou de realizar o levantamento junto aos Agentes Comunitários de Saúde (ACS) sobre a existência de casos, uma vez que desconheciam; e em outras três USFs houve completo desconhecimento da problemática e resistência dos coordenadores dos serviços para colaborar com o estudo.

Após esse levantamento, identificamos 15 casos, assim distribuídos: quatro na $1^{\mathrm{a}}$ região de saúde, sete na $2^{\mathrm{a}}$ região (sendo três pertencentes à mesma USF), dois na $3^{\text {a }}$ região e dois na $4^{\text {a }}$ região. Foram realizadas visitas às respectivas residências com o auxílio do ACS responsável. Durante a visita foi observado aspectos da dinâmica, rotina e condições de vida da família, além da realização da entrevista com o familiar cuidador. 
Nas visitas domiciliares, identificamos dois casos que não configurava como cárcere. $\mathrm{O}$ primeiro tratava-se de um quadro de sofrimento com retraimento social em que o usuário isolava-se em um dos cômodos da casa. O outro tratava de situação de negligência por parte dos cuidadores. Identificamos um terceiro caso em que não foi possível localizar o endereço, a família tinha mudado. Nos outros dois não foi possível realizar a entrevista devido à recusa da família, apesar da confirmação da existência de cárcere. Em resumo, dos 12 casos que conseguimos mapear no município entrevistamos dez.

Quanto aos profissionais, entrevistamos 15, entre eles: sete enfermeiras da ESF (coordenadoras da USF); dois psicólogos e uma assistente social do CAPS II; além da coordenadora do serviço (que é psicóloga), duas psicólogas e duas assistentes sociais das equipes NASF.

A etapa de identificação dos casos junto às equipes, e posteriormente das visitas domiciliares, sinalizou algumas dificuldades no trabalho de campo realizado, seja pela delicadeza do tema, seja pela demanda reprimida em saúde mental pela APS. Entre as principais, estiveram: a inconsistência das informações e o desconhecimento de casos em saúde mental nos territórios adscritos pelos serviços. Em algumas situações encontramos profissionais da ESF relatando casos graves de saúde mental no território como sendo de cárcere. Na verdade, percebemos que os ACS demandavam visitas, não por se tratar de casos de cárcere, mas como busca de algum recurso de apoio e suporte para as famílias com usuários em intenso sofrimento psíquico, e que não tinham a acolhida necessária da rede especializada do município. Afora a resistência de alguns profissionais e familiares que preferiram esconder ou ignorar situações de saúde mental em seus territórios, tivemos situações em que identificamos alguns casos ao percorrer as ruas do território, sendo revelados por ACS e moradores, na medida em que amadurecíamos as relações de vínculo com eles e com a comunidade.

\section{Caracterização dos Casos de Cárcere}

Os casos de cárcere privado identificados na pesquisa estão configurados da seguinte forma: cinco casos de situação de privação total de liberdade - os pacientes viviam encarcerados em quartos com grades sem qualquer possibilidade de trânsito por outros cômodos da casa; três casos em que os usuários circulam de forma limitada por outros cômodos da casa durante o dia, no entanto, à noite ou nas situações de crise, eles ficavam isolados em quartos com grades; os outros dois casos não se encontravam no momento da entrevista em situação de cárcere, pois um deles estava internado no Hospital Psiquiátrico na capital do estado, e o outro, depois de vários anos em situação de cárcere, encontrava-se com trânsito livre em casa por não apresentar comportamentos agressivos. Porém, no caso deste último, qualquer manifestação de nova crise, a família referiu que poderia recorrer novamente ao quarto cela, sem medo ou culpa.

Dos 10 casos registrados, sete são do sexo masculino e três do sexo feminino, com idade variando entre 21 a 52 anos. Em relação ao diagnóstico, sete cuidadores não souberam especificá-lo; dois sofrem de esquizofrenia e um de depressão grave. Nove entre os casos encontrados fazem uso de medicamentos (antipsicóticos, neurolépticos, estabilizadores de humor, anticonvulsionante e benzodiazepínicos) a longo prazo, que não são revisados há mais de um ano. Sendo que muitos dos medicamentos referidos foram prescritos depois da última internação, cujo tempo médio foi superior a quatro anos. Os medicamentos foram adquiridos com recursos próprios dos familiares, com exceção de um dos casos. Em relação à internação, nove possuem histórico de internações psiquiátricas tanto na capital $(n=1)$ quanto no município $(n=8)$, na ala psiquiátrica de um hospital filantrópico, espécie de manicômio local, e no antigo hospital-dia, transformado em CAPS II.

\section{Sofrimentos Familiares}

Sobre os cuidadores, a maioria é do sexo feminino. Apesar de as famílias serem numerosas na maioria dos casos visitados, seis deles são cuidados por somente um membro familiar (esposa, marido, mãe, pai ou irmã); três são cuidados por dois membros (mãe e irmãos); e somente um é cuidado por três membros (mãe, pai e irmãos). 
Entre os cuidadores, alguns são idosos e estão com idade avançada, e contam com pouco apoio dos mais jovens. Há ainda aqueles que são, praticamente, os únicos familiares $(n=2)$ na casa e que vivem com o usuário em situação de cárcere. Outros, apesar de morarem e cuidarem sozinhos $(n=2)$ do usuário, contam com outros familiares (a maioria filhos) que moram próximo $\mathrm{e}$, às vezes, prestam alguma ajuda. Os demais $(n=6)$ moram com um número maior de familiares, chegando a contar com cerca de oito pessoas na mesma casa, alguns, inclusive, são portadores de transtorno mental.

Quanto à renda, o cuidador é o responsável pelo sustento da casa, pois ou conta com algum trabalho (esporádico), na maioria das vezes, ou aposentadoria, no valor não maior que um salário. É importante registrar que em seis das casas visitadas, o usuário em situação de cárcere, ele próprio é o titular da aposentadoria ou de algum benefício social que é o sustento da família. Portanto, no geral, são famílias de baixa renda, sendo que algumas vivem próximas aos padrões estabelecidos de pobreza.

Tal realidade reafirma o lugar das mulheres como as mais envolvidas com as ações de cuidado e que acabam sendo as únicas responsáveis por este fazer. Por outro lado, também encontramos, em menor número, cuidadores masculinos. Percebe-se, portanto, atravessamentos das relações de gênero nas práticas de cuidado entre os entrevistados, figurando para a mulher o dever e a obrigação do cuidar, associado a carga física e emocional com o desgaste acumulado ao longo de anos, o que gera sofrimento, adoecimento e medicalização. Quanto ao homem, figura como benfeitor por doar o seu tempo para ser cuidador, sendo que para alguns, trata-se de uma obrigação devido não contarem com outro familiar para dividir tal tarefa. Porém, diferentemente do cuidado feminino, que normalmente é mais protetor, as ações de cuidado realizadas por homens são percebidas como mais geradoras de autonomia, além da imposição de limites ao paciente (Rosa, 2009).

É importante ressaltar ainda as transformações da atualidade que passam as famílias, independentemente da classe social e da localidade em que vivem. Rosa (2009) argumenta que, cada vez mais, as famílias têm diminuído de tamanho, o que faz com que tenham menos pessoas disponíveis para prover cuidados, além das múltiplas jornadas de trabalho da mulher com a inserção no mercado de trabalho, que tem que se dividir entre trabalhos domésticos, cuidados com os filhos, esposo e demais membros da família e o emprego. Os casos de divórcios/separações conjugais e o aumento de famílias monoparentais chefiadas por mulheres, sobretudo por idosas, com a pouca participação e auxílio dos mais jovens (filhos e netos), são cada vez mais recorrentes, o que torna ainda mais difícil, além da sobrecarrega, as ações de cuidado em saúde mental no domicílio.

Sobre o entendimento dos familiares sobre os motivos do adoecimento dos casos identificados, dentre os poucos que sabiam falar a respeito, alegavam motivos referentes ao adoecimento no período da infância, consequência do parto e outras cirurgias, lesão na cabeça devido algum acidente, e consequência do uso de drogas. Percebeu-se ao longo das visitas que os familiares não demonstravam preocupação em saber a respeito do transtorno mental do parente, nem das causas ou do diagnóstico, se contentando apenas com explicações do senso comum ou reproduzidas a partir de uma eventual consulta médica. Os familiares demonstravam maior preocupação em relação ao poder da medicação em resolver ou não o problema, ou pelo menos controlar aspectos relacionados ao transtorno, como agressividade, agitação, etc.

Sobre os cuidados prestados no dia-a-dia pelos familiares, pelo menos três afirmaram que não possuem dificuldades em realizá-lo; por outro lado, sete afirmaram que as dificuldades são muitas, entre as principais citaram: a agressividade do paciente, a limpeza do quarto, as situações estressoras e conflitivas que são constantes em seus cotidianos, sobrecarga e cansaço, além da dependência que o paciente apresenta para desenvolver qualquer ação, mesmo a menor que seja.

Quanto à interferência na rotina da casa, cinco familiares afirmaram não existir. Justificaram sua resposta no fato de que ou já se acostumaram com a situação, ou porque o paciente faz quase tudo sozinho, demonstrando certa independên- 
cia. Para os demais, as respostas indicaram que o cuidado com o paciente interfere sobremaneira em suas rotinas, especialmente no tocante: falta de autonomia e dependência do usuário, cansaço e agitação dos outros membros da família. A maioria dos familiares que não se queixaram de dependência por parte do portador de transtorno mental são os que deixam o paciente todo o tempo encarcerado no quarto.

Nas situações de crise, quatro entre os cuidadores entrevistados afirmaram não recorrer a ninguém, apenas trancam o paciente no quarto, administram a medicação e esperam o tempo necessário para a crise cessar; quatro afirmaram que recorrem a familiares próximos; e somente dois disseram recorrer a serviços do município, como por exemplo, o SAMU para medicar ou levar para internação.

Com relação ao modo como o familiar se sente tendo a responsabilidade de cuidar de alguém com transtorno mental no próprio domicílio, três afirmaram não se incomodar mais, pois se acostumaram com a situação, e sete afirmaram que vivem uma situação extremamente difícil e de profunda tristeza. Como suporte para lidar com essa situação, os entrevistados referem recorrer à religião, outros responderam que se resignaram no conformismo. Mas a maior parte reclamou da sobrecarga que é o trabalho de cuidado de um paciente de saúde mental em casa.

Sobre os cuidados oferecidos pelas equipes de saúde, quatro cuidadores relataram não serem assistidos por qualquer profissional, quer seja da ESF (médico, enfermeiro ou agente comunitário de saúde) e NASF, quer seja do CAPS. Ou seja, relataram que estão praticamente em situação de abandono. Não obstante, seis entre os cuidadores relataram que as equipes de saúde do município conhecem a situação da família, mas não têm realizado o acompanhamento mínimo necessário. Uma das cuidadoras, que estava visivelmente alcoolizada no momento da entrevista, afirmou que participa de atividades/orientações na USF, mas que as equipes não vão até a sua casa acompanhar o seu parente. Oito entre os entrevistados afirmaram que não participam de quaisquer atividades nos serviços, porque entendem que não são oferecidas atividades voltadas para eles. Por outro lado, três entre os entrevistados disseram que também recorrem ao uso de medicamentos psiquiátricos para suportar a sobrecarga e a vida que se encontram.

Sobre os prontuários dos usuários, os poucos que tivemos acesso estavam desatualizados em relação a data das últimas visitas realizadas. Algumas datavam um tempo maior que um ano, com o registro de medicamentos que estavam em desacordo com os atuais apresentados pelos entrevistados. Além disso, nos prontuários também não constava o diagnóstico do paciente, apesar do registro de visitas por membros da equipe ESF e NASF. No máximo, esses profissionais registravam o quadro de desordem e agitação, além das condições em que se encontrava o paciente, no quarto cela.

Quando foram indagados sobre o apoio da comunidade, vizinhos, igreja ou outro equipamento comunitário, somente um dos cuidadores referiu receber suporte dos grupos religiosos. Além deste, outro referiu que recebe algumas vezes apoio dos vizinhos nas situações de crise. Quando perguntados sobre como são percebidos pela comunidade, quatro entrevistados afirmaram que sofrem preconceito por parte da vizinhança, e seis afirmaram que apesar de terem sofrido preconceito no começo, hoje não se sentem mais atingidos.

Por fim, em relação aos motivos que levaram os familiares a optar por manter parentes com sofrimento psíquico em cárcere privado, metade dos entrevistados disseram que recorrem a esse tipo de situação por temerem pela própria segurança do paciente, especialmente para protegê-los, para não vê-los fugindo ou perambulando pelas ruas. Quatro entre os entrevistados afirmaram que trancam o paciente por ele apresentar agitação e comportamento violento, além do fato desse tipo de recurso ser uma forma de garantir momentos de tranquilidade em casa. Um outro alegou que recorreu a esse tipo de situação a pedido do próprio paciente que pediu para que ficasse preso num quarto em domicilio.

No geral, os familiares entrevistados relataram histórias de agressividade dos pacientes, em que estes destruíam objetos do quarto, inclusive 
as peças de louça do banheiro, e algumas vezes ateavam fogo em todo o cômodo. Lembraram que na época que tinham livre trânsito em casa, inclusive de sair à rua, era comum os pacientes ameaçarem e baterem nas pessoas.

Os relatos deram maior ênfase às situações de cronicidade, incapacidade para o trabalho e, especialmente, quanto a periculosidade e a impossibilidade de reintegração social dos seus parentes. Essas são concepções ainda muito fortes no imaginário cultural local. E, se antes, o isolamento das pessoas com problemas mentais, internando-a num hospital, era uma prerrogativa para a terapêutica, com a mudança para as formas de tratamento e cuidado extra hospitalar, com foco no território, envolvendo a família e a comunidade, isso fez com que o núcleo familiar se figurasse tanto como corresponsável do cuidado/suporte social, quanto como demandante de cuidados em saúde mental (Melman, 2001).

Assim, assumir o manejo do cuidado do paciente na vida cotidiana, entendendo a complexidade que é relacionar-se com o paciente e enfrentar as situações de crise e conflitos (Colvero, Ide, \& Rolim, 2004), isso acabou por exigir da família determinadas funções que historicamente lhes foi tirada. Além do que, nesse tempo, os seus saberes e práticas foram desconsiderados, passando a meros consumidores do modelo biomédico (Rosa, 2009). Por isso que os relatos dos entrevistados dão tanto crédito ao poder da medicação; e se esta não consegue resolver o problema, pelo menos controla o paciente.

Tal quadro acabou por produzir nas famílias forte sobrecarga de diferentes tipos (financeira, física, emocional ou referente ao cuidado), isolamento social, além de sentimentos de impotência, culpa, desespero, desamparo, exaustão e incapacidade para o cuidado (Borba, Schwartz, \& Kantorski, 2008; Rosa, 2009). Condição que justifica a ênfase dada nas entrevistas dos familiares em relação a agressividade e a dependência do paciente no manejo de situações mais simples da vida cotidiana.

As conversas com os familiares indicaram sobrecarga e intenso sofrimento com relação a conviver com uma pessoa com transtorno mental, e o fato de ainda terem que recorrer à situação de cárcere. Assumir a existência de um transtorno mental no meio familiar, ainda mais em situação cárcere, gera muita ansiedade e tensão no grupo (Rosa, 2009). Tal tensão permeia tanto o ambiente quanto a dinâmica familiar, além das relações com os vizinhos, muitas vezes devido ao receio de denúncia. A fala de uma das mães entrevistadas, que cuida de dois filhos com transtorno mental, sendo um mantido em cárcere, é reveladora desta situação:-“Dói quando ouço as batidas nas grades" (F5). Esta e outras situações com que nos defrontamos com os entrevistados denuncia a falta de retaguarda e ações de cuidado para toda a família.

\section{Dificuldades das Equipes Profissionais}

Sobre como os serviços e os profissionais têm se posicionado frente às situações de cárcere privado no município, identificamos certo descompasso entre as informações e registros sobre os casos relacionados. Constatamos a falta de qualquer acompanhamento epidemiológico e planejamento do trabalho pelas equipes (ESF, NASF e CAPS) frente aos casos de saúde mental, e muitos menos dos casos de cárcere privado identificados neste estudo. Enquanto os profissionais da ESF relatam a existência de vários casos, os profissionais do CAPS II e do próprio NASF desconhecem a maior parte deles. Como referimos antes, identificamos dez localidades, vinculadas as USFs do município, que contam com situações de cárcere. Sendo que, em somente uma delas, há o registro de três casos. Contudo, somente os profissionais de seis unidades de saúde relataram conhecerem os casos.

Para lidar com os casos, as equipes referiram realizar visitas domiciliares, atualizar vacinas, realizar ações dos programas de saúde com a família e encaminhar para outros serviços. Referiram ainda buscar apoio de outras instituições, pois tinham consciência de que somente a ESF não teria condições de articular ações efetivas para o caso. No entanto, de acordo com os entrevistados da ESF, a articulação com outros serviços era sempre pouco efetiva para os casos de saúde mental. A chegada do NASF, conforme relatou a ESF, foi fundamental para que fosse dado início as articulações e o apoio dos casos 
em geral, de saúde mental, e de cárcere privado em particular.

Com o NASF foi iniciado um processo de desambulatorização da APS do município devido a introdução de novos processos de trabalho: atividades coletivas com a população usuária, reuniões de equipe, discussão de casos, matriciamento e elaboração de projetos terapêuticos. Dos cinco profissionais das equipes NASF entrevistados, quatro relataram ter uma postura mais próxima dos casos de cárcere privado com os quais têm conhecimento $(n=5)$. O quinto profissional relatou não ter conhecimento sobre nenhum caso em seu território de atuação, apesar de haver situações de cárcere na região de saúde que é responsável. Dentre as ações desenvolvidas pelo NASF estão as visitas domiciliares, verificação da problemática, encaminhamento à rede de suporte e acompanhamento compartilhado do caso.

Quanto ao CAPS, os profissionais relataram que fazem reuniões entre si para discutirem a respeito dos casos de cárcere que têm conhecimento, que são somente dois entre os dez identificados. Relataram ainda que escalam membros da equipe para realizarem visitas, para saber se há acompanhamento médico e medicamentoso, buscam sensibilizar a família para buscar internação ou acompanhamento do serviço, além de conhecerem a condição de saúde e de vida do usuário. Entretanto, também reclamam sobre a dificuldade de trabalhar em conjunto com os outros serviços.

No geral, as maiores dificuldades e desafios apontados para a assistência dos casos de cárcere foram: a falta de integração dos serviços; melhoria na qualificação do cuidado e na gestão do trabalho com investimentos na formação técnica das equipes; melhor estrutura e condições de trabalho; aumento da retaguarda dos serviços especializados; e falta de apoio da gestão municipal.

Nesse sentido, Nunes, Juca e Valentim (2007) ressaltam que a articulação entre os diversos dispositivos de saúde é de suma importância para que possam ser realizados os cuidados em saúde mental de forma efetiva no território e para operar o processo de reabilitação psicossocial. O trabalho em rede requer o comprometimento de todas as organizações sanitárias e conexões com as diversas políticas públicas, pressupondo que nenhum serviço sozinho pode resolver todas as necessidades de cuidado das pessoas de um dado território, muito menos questões de maior complexidade, como os casos de cárcere privado e sobrecarga, desgaste, sofrimento e esgotamento da família.

Por outro lado, apesar de legítima a posição dos profissionais de apontarem as dificuldades para reverter os casos de cárcere privado pela via do cuidado sem recorrer ao denuncismo, é preciso ter clareza que o trabalho em rede, tanto reivindicado pelas equipes entrevistadas, exige outros modos de realizar o trabalho em saúde. Para que a rede de fato funcione é preciso que cada serviço ou equipe garanta a continuidade, o monitoramento e a avaliação permanente das ações de cuidado propostas. Ou seja, é preciso uma intensa coordenação do cuidado de modo que articule os diversos pontos da rede (sanitária e social) e suas estratégias de derivação, ampliando o acesso e a capacidade de oferecer respostas ao conjunto de necessidades das famílias. Assim, não basta apenas realizar "uma" ou "duas" visitas, levar este ou aquele profissional para realizar uma consulta, como percebido nos relatos das entrevistas que realizamos. Principalmente, se a expectativa da maioria deles é encontrar em algum ponto da rede o serviço que se apresente competente o suficiente para resolver ou dar respostas mais efetivas para o caso.

É preciso, portanto, estabelecer uma rotina e um planejamento do acompanhamento dos casos; identificar o campo de necessidades do paciente e da família; manejar e fortalecer o vínculo e o acolhimento das demandas da família como um todo, de modo a assisti-los coordenando as demais intervenções possíveis de serem realizadas pelos demais profissionais, equipes e serviços.

Para tanto, é preciso traçar planos de cuidado e projetos terapêuticos que possam ser executados por um conjunto de serviços e equipes de maneira articulada. No entanto, é preciso criar dispositivos de gerenciamento, acompanhamento e coordenação do cuidado, executado em parceria e de forma corresponsabilizada, que priori- 
ze a avaliação integral do paciente e da família, considerando as dimensões clínica, social-comunitária, psicopatológica e das necessidades em termos do autocuidado e gestão do cotidiano; sobrecarga e desgastes; autonomia; relações interpessoais, lazer e tempo livre; funcionamento cognitivo, funcionamento ou expectativas sobre o trabalho; propostas de tratamento e cuidado, etc. Os desenhos de cuidado precisam ser individualizados, porém, com revisão e atualização periódica e permanente (Dimenstein, 2013; Dimenstein, Lima, \& Macedo, 2013).

O objetivo é criar espaços de cuidado de modo a fortalecer o acolhimento e o vínculo de tal modo que seja possível construir as estratégias de ação em conjunto com o paciente e a família, mesmo que isso demande tempo e investimento afetivo relacional. Tais aspectos, por exemplo, não foram visualizados nas ações descritas pelos entrevistados. Pelo contrário, o que percebemos foi a cronificação das práticas das equipes, com a aposta em ações com baixa capacidade de elegerem ou investirem novas atividades/práticas, ou ainda de introduzirem algumas variações no seu repertório técnico-profissional de modo a evitar que as mesmas se fixem em rotinas tanto para as famílias quanto para os próprios profissionais.

Daí o motivo de alguns profissionais demonstrarem cansaço e descrédito frente a um trabalho que é ao mesmo tempo tenso e intensivo, e por vezes ainda torna-se repetitivo, já que o máximo que se avançou, conforme relatado pelos profissionais entrevistados, foi em relação as reuniões de equipe para discutirem possíveis encaminhamentos, que esbarram na fragilidade da integração dos serviços. Como desdobramento, percebemos também a cronicidade da rede devido à fragilidade e a existência de "um conjunto de pontos ligados frágil e burocraticamente" (Barros, 2003, p. 205). Deste modo, torna-se mais difícil ainda o empreendimento de ações que avancem na desmontagem do cárcere, o que reforça sua institucionalização, considerando que tais situações se arrastam por anos, com conhecimento das autoridades locais.

Quando perguntados como os profissionais percebiam as famílias dos casos em cárcere pri- vado, alguns responderam que os familiares eram indiferentes, acomodados, que tratavam os casos com desprezo, eram negligentes, desinformados, não sabiam cuidar, ou seja, responsabilizando-os e julgando-os. - "Despreparada para lidar com paciente psiquiátrico" (P13). - "São totalmente assim sem conhecimento, totalmente desinformados" (P15). Outros percebiam as famílias como exaustas, em processo de adoecimento, demandantes de cuidado devido os níveis de sofrimento e desesperança em que se encontravam.

É fato que as famílias ainda não se percebem como parte fundamental no processo de cuidado, até mesmo porque historicamente foram excluídas deste lugar. Contudo, é comum os atuais serviços de saúde desconsiderarem a potência cuidadora das famílias, além do fato destas também serem demandantes de cuidado (Colvero et al., 2004). Mesmo porque o cuidado não é algo natural, algo que as famílias têm como saber dado. Pelo contrário, trata-se de algo complexo. É preciso superar a ideia naturalizada de que a ação de cuidado é simplesmente um sentimento de querer bem o outro, de protegêlo. $\mathrm{Na}$ verdade, é preciso aprender a cuidar. A família e os profissionais aprendem a cuidar na base do ensaio-e-erro, pois não há fórmulapadrão para o cuidado no ambiente doméstico (Rosa, 2009).

Perguntados que papel a família teria como agente de cuidado, 13 entre os profissionais entrevistados referiram que a família teria um papel fundamental e de extrema importância, mas que ela própria também necessitaria de suporte. Os outros profissionais desacreditaram da potencialidade das famílias como agente de cuidado, pois, para eles, os familiares estão acomodados e apresentam pouco interesse em cuidar do seu parente, situação que para os entrevistados denota negligência. Rosa (2009) afirma que a família tem um papel fundamental na elaboração de novos projetos e possibilidades de cuidado junto ao portador de transtorno mental, para tanto seus recursos emocionais, temporais, econômicos e seus saberes precisam ser bem direcionados, cabendo aí o auxílio dos profissionais e dos serviços de atenção psicossocial para favorecer novas ações de cuidado. 
Sobre as necessidades e suporte que as famílias demandariam para constituírem-se como agentes de cuidado, os profissionais foram unânimes em admitir que elas necessitariam serem assistidas em vários âmbitos: maior apoio psicossocial; um trabalho em rede com o apoio de outras instituições e outros profissionais; suporte e apoio da comunidade; sensibilização, orientação e esclarecimento; além do apoio financeiro, para que estas famílias desenvolvam maior autonomia no cuidado de seus entes.

Porém, ao serem indagados sobre quais ações de cuidado os profissionais têm desenvolvido junto às famílias, a maioria dos entrevistados relataram realizar apenas visitas domiciliares, a fim de orientar e conversar com a família quanto à medicação, aferir a pressão e, se for o caso, fazer algum encaminhamento a outros serviços. A justificativa recai novamente na falta de estrutura e suporte da rede, sem qualquer avaliação sobre o que é possível fazer a partir do serviço que estes profissionais estão vinculados, para se avançar na maior atenção aos casos e apoio às famílias.

\section{Considerações Finais}

Além das dificuldades de acesso e garantira de direitos, a complexidade da problemática do cárcere privado traduz o quanto que a "vertente da integralidade" é atravessada pelas "adversidades das equipes" e pela "burocracia e fragmentação do cuidado" (Jorge \& Pinto, 2010, p. 337). Neste trabalho procuramos investigar os modos com que familiares e profissionais lidam com a problemática do cárcere privado em Parnaíba. Buscamos, inclusive, acompanhar as equipes de três diferentes equipamentos da rede de atenção psicossocial (ESF, NASF e CAPS) do município para identificar os desafios postos neste tipo de assistência. Entre os principais achados estão: a ocorrência significativa de casos de cárcere, afora aqueles que ainda estão velados e que não conseguimos identificar; a fragilidade da assistência aos casos na perspectiva de reverter tal situação, apesar do conhecimento dos profissionais, gestores e autoridades; e a quase nenhuma oferta de cuidados aos familiares, que estão sufocados em seu cotidiano pela sobrecarga e in- tenso sofrimento e esgotamento frente à missão solitária do cuidado em saúde mental no contexto domiciliar.

Também ficou patente a contradição entre os relatos dos familiares de que não são assistidos por qualquer profissional de saúde, ou de que são assistidos de forma insuficiente, com o relato dos profissionais de que têm conhecimento e que prestam a assistência necessária (visitas domiciliares) aos casos, apesar de esbarrarem na falta de respostas da rede. Compreendemos a tensão posta como um analisador dos inúmeros entraves que passa a saúde mental do município. Por um lado os profissionais responsabilizam as famílias e a falta do trabalho em rede como os principais fatores para o insucesso quanto a reversão das situações de cárcere em Parnaíba. Por outro, a dificuldade técnica e a falta de organização dos processos de trabalho das equipes, na perspectiva da clínica do cuidado, para realizar o acompanhamento sistemático das famílias; a dificuldade em descentrar as ações profissionais das rotinas técnicas dos serviços e focar nas necessidades dos usuários, família e entorno; a pouca diversificação da oferta terapêutica e ações de cuidado voltadas para o território e reabilitação psicossocial; e a dificuldade de realizar ações de gestão compartilhada dos casos e a coordenação do cuidado de modo a coresponsabilizar diferentes níveis de complexidade da atenção, isso tudo fragiliza ainda mais qualquer articulação ou tentativa do trabalho em rede (Dimenstein, 2013; Dimenstein et al., 2013).

Nesse sentido, é preciso construir parcerias, desenvolver habilidades, novas tecnologias relacionais do cuidado. Posturas de julgamento, culpabilização e desvalorização do saber do outro, como vimos ao longo deste estudo, torna ainda mais difícil qualquer tipo de vínculo e escuta das famílias para que se possa identificar os cuidados demandados, além de compreender as percepções quanto "o desencadeamento do problema, o curso, o impacto no cotidiano e formas de tratamento dos que se encontram em sofrimento mental" (Pegoraro \& Caldana, 2008, p. 296). Tais ações, conforme alertam os autores, permite a instrumentalização técnica das equipes na avaliação do modo como se percebe o pro- 
blema/situação enfrentada pelas famílias, o grau de crítica da realidade, os conhecimentos sobre a doença, além dos manejos e estratégias que eles recorrem nas mais variadas situações que têm que lidar com os casos sob sua responsabilidade nos seus domicílios.

Talvez uma das principais estratégias geradoras de vínculo nestes casos seja o acolhimento do sofrimento e do esgotamento advindo da sobrecarga na prestação de cuidados à família, como foco nos indivíduos mais fragilizados. Conhecer este universo não só aproxima a equipe da família, como também pode ser muito potencializador e, talvez, quem sabe, reparador das relações, que por muito tempo ficaram desgastadas, entre família e o usuário em situação de cárcere.

Espera-se com esse estudo dar conhecimento a uma das realidades mais duras e difíceis do trabalho em saúde mental, e urgente de respostas da rede de atenção psicossocial. Especialmente porque reafirma a bandeira de luta por uma sociedade sem manicômios e fortalece a luta por cidadania e a defesa dos direitos humanos frente a uma problemática que de longe é exclusiva do município de Parnaíba, no Piauí.

\section{Referências}

Barros, R. B. (2003). Reforma Psiquiátrica Brasileira: Resistências e capturas em tempos neoliberais. In Conselho Federal de Psicologia, Loucura, ética e política: Escritos militantes (pp. 196-206). São Paulo, SP: Casa do Psicólogo.

Borba, L. O., Schwartz, E., \& Kantorski, L. P. (2008).

A sobrecarga da família que convive com a realidade do transtorno mental. Acta Paulista de Enfermagem, 21(4), 588-594. Recuperado em www.scielo.br/pdf/ape/v21n4/a09v21n4.pdf

Colvero, L. A., Ide, C. A. C., \& Rolim, M. A. (2004). Família e doença mental: A difícil convivência com a diferença. Revista da Escola de Enfermagem USP, 38(2), 197-205. Recuperado em http://www.scielo.br/pdf/reeusp/v38n2/11.pdf

Dias, M. K., Ferigato, S., \& Biegas, M. O. C. (2010). Cultura manicomial além do hospital: $O$ estudo dos cárceres privados em Caicó (RN). In F. B. Campos \& A. Lancetti (Eds.), Saúde Loucura: Vol. 9 (pp. 49-71). São Paulo, SP: Hucitec.

Dimenstein, M. (2013). La Reforma Psiquiátrica y el modelo de Atención Psicosocial en Brasil: en busca de cuidados continuados e integrados en Salud Mental. Revista CS (Cáli), 11, 43-72. doi:10.18046/recs.i11.1566

Dimenstein, M., Lima, A. I. O., \& Macedo, J. P. (2013). Integralidade em Saúde Mental: Coordenação e continuidade de cuidados na atenção primária. In S. Paulon \& R. Neves (Eds.), Saúde mental na atenção básica (pp. 39-60). Porto Alegre, RS: Sulinas.

Jorge, M. S. B., \& Pinto, A. G. A. (2010). Adoecimento mental e a família. In L. A. B. Trad (Ed.), Família contemporânea e saúde (pp. 312-334). Rio de Janeiro, RJ: Fundação Oswaldo Cruz.

Melman, J. (2001). Família e doença mental. São Paulo, SP: Escritus.

Minayo, M. C. S. (2006). O desafio do conhecimento: Pesquisa qualitativa em saúde (9. ed.). São Paulo, SP: Hucitec.

Ministério da Saúde. (2009). Diretrizes do Núcleo de Apoio a Saúde da Família. Cadernos da Atenção Básica, 27.

Nunes, M., Juca, V. J., \& Valentim, C. P. B. (2007). Ações de saúde mental no Programa Saúde da Família: Confluências e dissonâncias das práticas com os princípios das reformas psiquiátrica e sanitária. Cadernos de Saúde Pública, 23(10), 2375-2384. doi:10.1590/S0102$-311 \times 2007001000012$

Organização Pan-Americana de Saúde, \& Ministério da Saúde. (2002). Relatório do Seminário Internacional sobre Saúde Mental na Atenção Básica. Cambridge, MA: Universidade de Harvard.

Pegoraro, R. F., \& Caldana, R. H. L. (2008). Sofrimento psíquico em familiares de usuários de um Centro de Atenção Psicossocial (CAPS). Interface - Comunicação, Saúde, Educação, 12(25), 295-307. Recuperado em http://www.scielo.br/ pdf/icse/v12n25/a06v1225.pdf

Rosa, L. (2009). A família como usuário de serviços e como sujeito político no processo de reforma psiquiátrica. In E. M. Vasconcelos, Abordagens psicossociais: Vol. 3. Perspectivas para o serviço social. São Paulo, SP: Hucitec.

World Health Organization. (2000). Cross-national comparisons of the prevalences and correlates of mental disorders. Bulletin World Health Organization, 78(4), 413-426. Retrieved from http:// www.who.int/bulletin/archives/78(4)413.pdf 